\title{
Which hemogram parameter is more cautionary in euthyroid patients with gestational diabetes mellitus
}

\author{
Saliha Yıldız ${ }^{1,{ }^{*}}$, Rıfkı Üçler ${ }^{1}$, Murat Alay ${ }^{1}$, Emine Bulut Ekici $^{2}$ \\ ${ }^{1} Y$ игиnси Yil University Medical Faculty Department of Endocrinology, Van \\ ${ }^{2}$ Private Lokman Hekim Van Hospital Department of Obstetrics and Gynecology, Van
}

\begin{abstract}
Gestational Diabetes Mellitus is the most diagnosed metabolic disease in pregnancy. The mother and fetus are affected both adversely for this disorder. Gestational Diabetes pathogenesis is associated with subchronic inflammation. The aim of this study was to compare the various hemogram parameters in euthyroid patients with Gestational Diabetes Mellitus and healthy pregnant controls and to determine which parameter is more cautionary for Gestational Diabetes Mellitus diagnosis.

This study was conducted in the Endocrinology Department of Van Training and Research Regional Hospital and Obstetrics and Gynecology Department of Private Lokman Hekïm Van Hospital. The 53 GDM patients and 35 healthy pregnant women, whose gestational age were higher than twenty four weeks and whose euthyroid, normotansive were included in the study. Statistically significant relationships between platelet count (PC), platelet distribution width (PDW), lymphocyte count (LC), neutrophil to lymphocyte ratio (NLR), platelet to lymphocyte ratio (PLR), red cell distribution width (RDW) and GDM disease were found (p; 0.000, 0.000,0.000, 0.000, 0.000, 0.007 respectively). Platelet distribution width had higher sensitivity and specificity than other parameters. Although platelet distribution width is a less known or an unconsidered parameter in complete blood count, it gives more precise information than other hemogram parameteres. It may be convenient to screen the gestational diabetes as an adjunct to oral glucose tolerance test.
\end{abstract}

Key Words: Gestational diabetes mellitus, platelet distribution width, platelet count, platelet to lymphocyte ratio, neutrophil to lymphocyte ratio

\section{Introduction}

Gestational Diabetes Mellitus is carbohydrate intolerance associated with hyperglycemia of variable levels during pregnancy. GDM is the most encountered metabolic disease in pregnancy, with a reported incidence ranging from 2 to $25 \%$ (1), with an increased incidence of older maternal age and increased obesity.

Gestational diabetes may have deleterious effects for both the mother and the fetus. Diabetes recognized during pregnancy with elevated fasting glucose concentrations is associated with the risk of intrauterine fetal death during the last periods of gestation and other complications including congenital abnormalities, fetal macrosomia. Jaundice, neonatal hypoglycemia, hypocalcemia and polycythemia are other fetal complications of GDM. Children of patients with GDM have a high risk of obesity, diabetes in adolescence or as young adults and glucose intolerance (2). In most patients with GDM, glucose intolerance resolved during the postpartum; however these patients have a lifetime risk of cardiovascular disease and type II diabetes (3).

GDM has been reported to be associated with subchronic inflammation (4). There are many data in the literature that states the central role of inflammation in the Type II Diabetes Mellitus, pathophysiology of obesity, cardiovascular complications and GDM.

In the initial evaluation of diseases, complete blood count $(\mathrm{CBC})$ is a laboratory test that is ordered routinely. It provides information about white blood cells (WBCs), red blood cells (RBCs), and platelets. Measuring the platelet-tolymphocyte ratio (PLR) and neutrophil-tolymphocyte ratio (NLR) provide a simple cheap method for the evaluation of inflammatory status. Platelet size, platelet distribution width and mean platelet volume (MPV) matches with the platelet activity. An increase in the MPV value has been presented in conditions closely associated with insulin resistance including hypertension, metabolic syndrome, impaired fasting glucose, obesity and DM $(5,6,7)$. 
The aim of this study was to compare the various hemogram parameters such as RDW, PLR, NLR, MPV, PDW in euthyroid patients with GDM and healthy pregnant controls and to determine which parameter is more cautionary for GDM diagnosis.

\section{Materials and methods}

This study was a cross-sectional, case-control study. The design of the study was approved by the Ethical Committee and Institutional Review Board of Van Training and Research Regional Hospital. The study was conducted in Van Training and Research Regional Hospital, department of endocrinology and Private Lokman Hekïm Van Hospital, department of obstetrics and gynecology. Written informed consents were obtained from participants.

Fifty three pregnant women clinically diagnosed as GDM were recruited from the Endocrinology Department of Van Training and Research Regional Hospital between December 2014 and May 2015. The age, gestational age and body mass index (BMI) - matched thirty five healthy pregnant women as control group were recruited from the Obstetrics and Gynecology Department of Private Lokman Hekïm Van Hospital at same period.

Age, gestational age, diastolic blood pressure and systolic blood pressure were recorded in all participants. Pregnancy body mass index (BMI) was measured as the ratio of weight divided by height squared $\left(\mathrm{kg} / \mathrm{m}^{2}\right)$. Criteria for exclusion was being younger than twenty four weeks of gestational age, clinic-subclinic hypothyroidism or clinic hyperthyroidism (TSH $\geq 3 \mathrm{mIU} / \mathrm{ml}$ or $<$ $0.1 \mathrm{mIU} / \mathrm{ml}, \mathrm{FT} 3<3.1$ or $>6.8 \mathrm{pmol} / \mathrm{lt}$, FT4 $<12$ or $>22 \mathrm{pmol} / \mathrm{lt})$, pregestational obesity $(\mathrm{BMI}>30)$, pregestational diabetes, hypertension ( $>130 / 85$ $\mathrm{mmHg}$, history of hypertension before pregnancy, inflammatory disease, myeloproliferative disorders, taking anticoagulant medicine, malignancy and infection or suspicion of infection (neutrophil count $>10000 / \mathrm{mm}^{3}$ ).

The patients and healthy pregnant women, whose gestational age were higher than twenty four weeks and whose euthyroid, normotansive did not have exclusion criterias, were included to the study.

Screening for GDM $50 \mathrm{~g}$ glucose challenge test was performed in all pregnant women after 24 weeks of gestation. Women with a $1 \mathrm{~h}$ glucose level of $140 \mathrm{mg} / \mathrm{dl}$ or higher were tested with 100 $\mathrm{g}$ oral glucose tolerance test (OGTT) and
Carpenter and Coustan guidelines were used. The women with two or more abnormal values were diagnosed as having GDM.

At the first visit measurements (blood samples and systolic-diastolic blood pressure, height, weight) were obtained and recorded from fifty three women with GDM. All of them were recommended with dietary advice. The insulin therapy were gave and recorded if they need it. Thirty five healthy pregnant women were also considered as control group.

The serum samples were obtained after overnight fasting, at the time of OGTT for the analysis and analyzed within $1 \mathrm{~h}$ of collection. Blood samples of the patients were analyzed with using an Automated Hematology Analyzer Sysmex XN 1000 for measurement of neutrophil, lymphocyte, PDW, MPV and RDW before the OGTT. In patient group $\mathrm{HbA} 1 \mathrm{C}$ were examined with Adams Arcray HA 8160 with high performance liquid chromatography method, free triiodothyronine (fT3), thyroid stimulating hormone (TSH), free thyroxin (fT4) with chemiluminescent method and fasting glucose, postprandial glucose with spectrophotometric method in cobas 8000 modular analyzer. The hemogram parameters of healthy pregnant group were determeined with using Swelab Alpha Hematology analyzer with volumetric impedence method. In this group only TSH levels were examined in COBAS C 601 device with chemiluminescent method and fasting glucose in COBAS C 501device with spectrophotometric method.

PLR was calculated by dividing the platetelet count by lymphocyte count, and NLR was calculated by dividing the neutrophil count by lymphocyte count.

Statistical analysis: SPSS software version 20 (SPSS, Chicago, IL, USA) was used for statistical analyses. Values were reported as means \pm standard deviation or medians (minimummaximum. Proportions were compared by using the Chi-square test or Fisher's exact test. The level of significance was established by using the student t-test for normally distributed values and Mann Whitney U test for abnormally distributed values. Correlation analysis was determined by using Spearman's rank correlation coefficent. A receiver-operating characteristic (ROC) analysis was conducted to specify the best cut-off value to predict the outcome. Differences were reflected as significant at $\mathrm{p}<0.05$. 


\section{Results}

There were 53 patients in the GDM group and 35 healthy pregnant women in the control group. Characteristics of the groups are given in table 1 . There was no statistically significant difference in patient age, BMI, gestational age between the groups ( $\mathrm{p}=0.141,0.138$ and 0.275 respectively). The means \pm SDs of $\mathrm{CBC}$ and other parameters are given in table $2 \mathrm{a}$ and $2 \mathrm{~b}$.

There was no statistically significant difference between the GDM and control groups with respect to hemoglobin (HGB), neutrophil count $(\mathrm{NC})$, mean corpuscular volume (MCV), mean platelet volüme (MPV) and fasting plasma glucose (FPG) $(\mathrm{p}>0.05)$.

Patients in the GDM group had significantly higher values of platelet count (PC), red cell distribution width (RDW), platelet-lymphocyte ratio (PLR), platelet distribution width (PDW) and neutrophil-lymphocyte ratio (NLR) and had significantly lower value of lymphocyte count (LC) than the control group $(\mathrm{p}=0.000,0.007,0.000$, $0.000,0.000$, and 0.000 respectively).
ROC analyses of PDW, PLR, PLT and NLR are shown in figure. In the ROC curve analysis, the PDW cut-off point for GDM development was 14.75, with a sensitivity, specificity, positive predictive value (PPV), and negative predictive value (NPV) of 96.4, 100, 100 and 94.8\%, respectively (AUC:1).

The patients were divided into two groups in respect to their need for insulin therapy (n:25) or not (n:28). Characteristics of the groups are given in table 3 . The insulin necessity group's pregnancy age was higher than the other group's (p: 0.009). The MPV was detected borderline different between groups. Insulin necessity group's MPV value was higher than the other group's but it was statistically insignificant $(p=0.061)$. There was no statistically significant difference between last two groups with respect to BMI, $\mathrm{Hb}, \mathrm{RDW}, \mathrm{PC}, \mathrm{PDW}$, LC, NC, PLR, NLR, FPG, first hour's postprandial plasma glucose level (PPG), HbA1C $(\mathrm{p}>0.05)$. The means \pm SDs and minimum maximum levels of determined parameters are given in table $4 \mathrm{a}$ and $4 \mathrm{~b}$.

Table 1. Demographic data of GDM group and control group

\begin{tabular}{llll}
\hline & Control group (n:53) & GDM group (n:35) & p \\
\hline Age & $29.57 \pm 4.26$ & $31.45 \pm 6.63$ & 0.141 \\
Gestational age (week) & $30.48 \pm 4.82$ & $28.96 \pm 4.17$ & 0.119 \\
BMI & $26.80 \pm 2.97$ & $27.85 \pm 3.35$ & 0.138 \\
\hline
\end{tabular}

Table 2a. Hemogram parameters of GDM group and control group (Student t-test)

\begin{tabular}{llll}
\hline & $\begin{array}{l}\text { GDM group (n:53) } \\
\text { means } \pm \text { standard deviation }\end{array}$ & $\begin{array}{l}\text { Control group (n:35) } \\
\text { means } \pm \text { standard deviation }\end{array}$ & $\mathrm{p}$ \\
\hline PDW (fL) & $16.240 \pm .3426$ & $10.689 \pm 1.3315$ & 0.000 \\
$\mathrm{RDW}(\%)$ & $13.588 \pm 1.059$ & $13.037 \pm 0.631$ & 0.007 \\
$\mathrm{MCV}(\mathrm{fL})$ & $87.948 \pm 6.255$ & $86.700 \pm 4.477$ & 0.312 \\
$\mathrm{MPV}(\%)$ & $10.054 \pm 1.149$ & 0.763 \\
$\mathrm{Hb}(\mathrm{g} / \mathrm{dl})$ & $9.975 \pm 1.222$ & $12.622 \pm 0.999$ & 0.661 \\
$\mathrm{NLR}$ & $12.517 \pm 1.157$ & $2.931 \pm 0.803$ & 0.000 \\
Neutrophil/ $\mathrm{mm}^{3}$ & $3.888 \pm 1.148$ & $6568.57 \pm 1382.61$ & 0.790 \\
Lymphocyte $/ \mathrm{mm}^{3}$ & $6653.96 \pm 1522.33$ & $2325.71 \pm 582.25$ & 0.000 \\
\hline
\end{tabular}

Table 2b. Mann Whitney U test for abnormally distributed values of GDM group and control group

\begin{tabular}{llll}
\hline & $\begin{array}{l}\text { GDM group (n:53) } \\
\text { medians (minimum-maximum) }\end{array}$ & $\begin{array}{l}\text { Control group (n:35) } \\
\text { medians (minimum-maximum) }\end{array}$ & $\mathrm{p}$ \\
\hline FPG $(\mathrm{mg} / \mathrm{dl})$ & $58-167.9$ & $68-91.4$ & 0.92 \\
Platelet count $/ \mathrm{mm}^{3}$ & $126000-494000$ & $102000-294000$ & 0.000 \\
PLR & $68.61-602.44$ & $44.33-202.73$ & 0.000 \\
\hline
\end{tabular}

East J Med Volume:21, Number:4, October-December/2016 


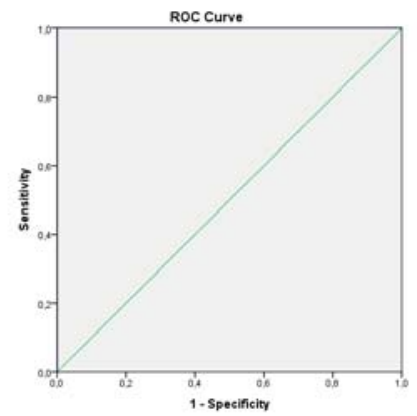

PDW AUC: 1
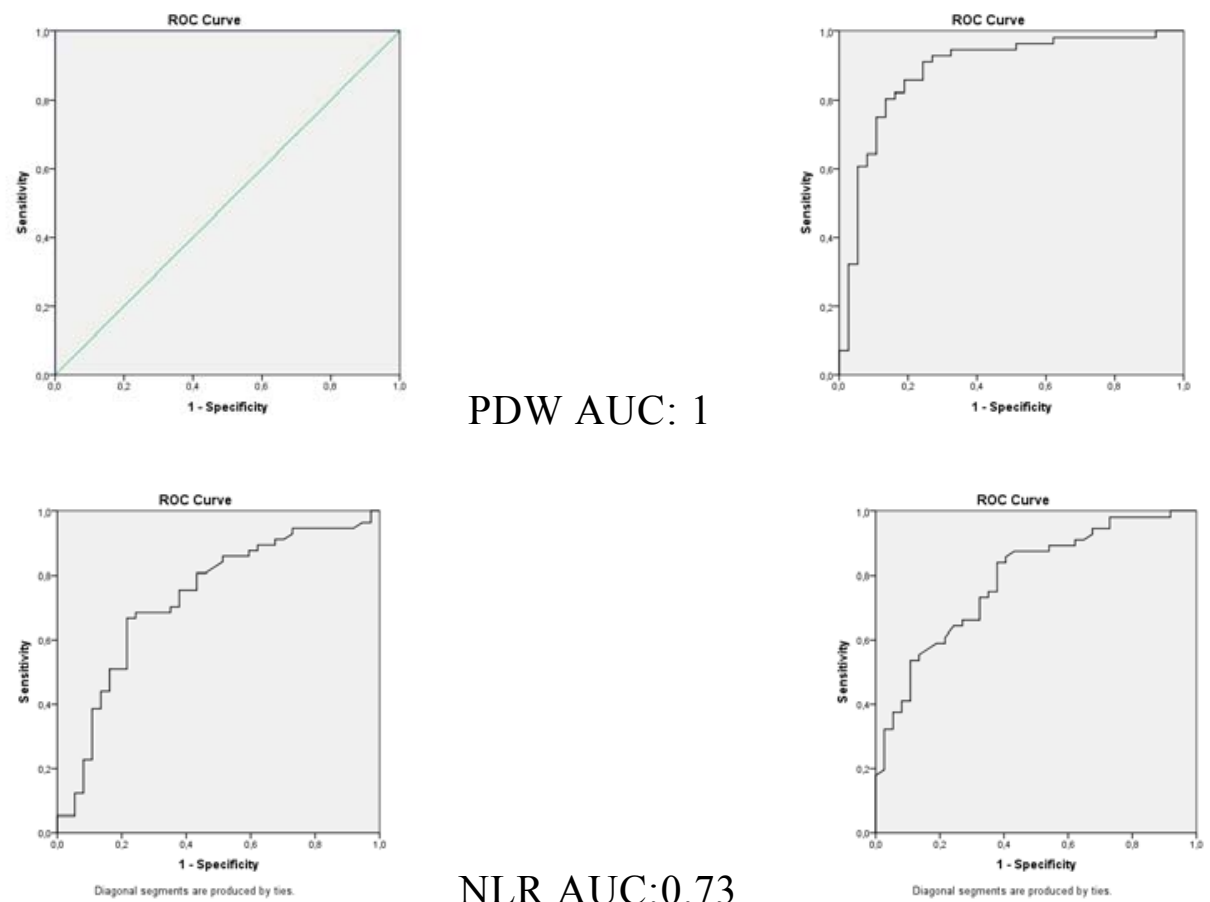

PLR AUC: 0.88

NLR AUC:0.73

PLT AUC: 0.787

Fig. ROC curve of PDW, PLR, NLR and PLT

Table 3. Demographic data of insulin necessity group and non-necessity group

\begin{tabular}{llll}
\hline & Insulin necessity (-) (n:28) & Insülin necessity (+) (n:25) & $\mathrm{p}$ \\
\hline Age & $30.75 \pm 6.204$ & $32.24 \pm 7.137$ & 0.420 \\
Gestational age (week) & $27.57 \pm 2.84$ & $30.52 \pm 4.89$ & 0.009 \\
BMI & $27.12 \pm 3.21$ & $28.68 \pm 3.38$ & 0.098 \\
\hline
\end{tabular}

Table 4a. Student T-test of insulin necessity group and non-necessity group

\begin{tabular}{llll}
\hline & $\begin{array}{l}\text { Insulin necessity present (n:25) } \\
\text { means } \pm \text { standard deviation }\end{array}$ & $\begin{array}{l}\text { Insulin necessity absent (n:28) } \\
\text { means } \pm \text { standard deviation }\end{array}$ & $\mathrm{p}$ \\
\hline PDW (fL) & $16.316 \pm 0.363$ & $16.170 \pm 0.312$ & 0.127 \\
$\mathrm{RDW}(\%)$ & $13.480 \pm 0.904$ & $13.688 \pm 1.193$ & 0.483 \\
$\mathrm{MPV}(\%)$ & $10.308 \pm 1.277$ & $9.679 \pm 1.110$ & 0.061 \\
Lymphocyte count/ $\mathrm{mm}^{3}$ & $1777.60 \pm 440.280$ & $1734.64 \pm 371.580$ & 0.702 \\
$\mathrm{NLR}$ & $3.766 \pm 1.108$ & $4.997 \pm 1.193$ & 0.470 \\
$\mathrm{PPG}(\mathrm{mg} / \mathrm{dl})$ & $146.417 \pm 42.815$ & $128.768 \pm 28.177$ & 0.142 \\
$\mathrm{Hb}(\mathrm{g} / \mathrm{dl})$ & $12.560 \pm 0.979$ & $12.477 \pm 1.318$ & 0.801 \\
Neutrophil count/ $\mathrm{mm}^{3}$ & $6518 \pm 1516.976$ & $6775.36 \pm 1544.470$ & 0.544 \\
\hline
\end{tabular}

Table 4b. Mann Withney $U$ test for abnormally distributed values of insulin necessity group and nonnecessity group

\begin{tabular}{llll}
\hline & $\begin{array}{l}\text { Insulin necessity present }(\mathrm{n}: 25) \\
\text { (minimum-maximum) }\end{array}$ & $\begin{array}{l}\text { Insulin necessity absent }(\mathrm{n}: 28) \\
\text { (minimum-maximum) }\end{array}$ & $\mathrm{p}$ \\
\hline FPG $(\mathrm{mg} / \mathrm{dl})$ & $58-167.9$ & $61-112$ & 0.31 \\
HbA1c $(\%)$ & $4.7-7.5$ & $4.5-5.8$ & 0.36 \\
Platelet count $/ \mathrm{mm}^{3}$ & $126000-297000$ & $144000-494000$ & 0.19 \\
PLR & $68.61-194.33$ & $96.55-602.44$ & 0.40 \\
\hline
\end{tabular}

East J Med Volume:21, Number:4, October-December/2016 


\section{Discussion}

The investigation of various hemogram parameters as inflammation markers in diseases with inflammation in the pathogenesis has attracted attention recently. The role of inflammation of pathogenesis in Diabetes Mellitus has been shown as well. Besides it has been determined that the inflammation precursors such as TNF $\alpha$, IL-6 have increased in patients with GDM patients and the existence of inflammation has been proven in some studies (4). In our study, we have showed that the indexes that may be related to inflammation in GDM have changed significantly; such as qualitative-quantitative platelet levels (platelet count, PDW, plateletlymphocyte ratio), neutrophil-lymphocyte ratio, erythrocyte distribution range.

Red cell Distribution Width measurement, which gives an idea about the size of a red blood cell heterogeneity, is a routine application in complete blood count. RDW's indirect association with inflammation has been proven before. The metaanalysis, which states that $1 \%$ increase of RDW is associated with the $14 \%$ mortality increase in patients with Diabetes Mellitus, is the leading motive behind the research of these parameter (8). The reason of the increase of DM can not be enlightened completely, however it can be associated with oxidative stress and rapid erythrocyte elimination (9). Any significant relation in respect of RDW between patients with GDM and healthy pregnant women has not been found in the study of Erdogan et al (10). Sahbaz et al (11) have studied RDW in patients with GDM and they have found significantly higher levels of RDW than the healthy pregnants. The RDW values were significantly high in patients with GDM in our study (p: 0.007) as well and it may be due to the inflammatory process.

Platelets were held responsible for thrombus formation for long time, however, it has been determined that by secretion of P-selection actually it is responsible for collection of inflammatory cells. CD62P (P-selectin), GP IIb/IIIa, platelet factor $4, \mathrm{CD} 63$, and $\beta$ thromboglobulin were used as markers of platelet activation (12). Because the analysis of these markers are expensive and time consuming, the platelet count, platelet indexes such as MPV, PDW and platelet / lymphocyte ratio are used to investigate this subject recently.

Conflicting results were obtained about the platelet count in patients with GDM in some studies. A significant difference in platelet count was not observed between the studies of Bozkurt et al (13) and Erdogan et al (10). The platelet count was found significantly lower than the control in the study of Erikçi et al (14). There are also studies in which the levels of platelet count were determined significantly higher in patients with GDM $(11,15)$. In our study we determined that the gestational diabetes increased the number of platelet significantly in compared with the control group.

PLR has been studied recently in type II diabetes patients and it has been found significantly higher than the control groups and it has been put forward as a inflammatory marker (16). Sahbaz et al (11) and Aktulay et al (4) have studied PLR in patients with GDM and they have found significantly higher levels of PLR than the healthy pregnants. Our study is the third study in literature that shows the high platelet lymphocyte ratio in diabetic pregnancies.

Once again the neutrophil-lymphocyte ratio is investigated as an inflammation marker in some diseases recently. Erdogan et al (10) and Yilmaz et al (17) have also studied this marker and they have detected it increased. Besides Yilmaz et al (17) have determined the significant limit as 2.93 for this parameter. In our study, NLR was significantly higher in patients with GDM as well and this increased went above the mentioned threshold (3.888 \pm 1.148$)$ and we have calculated the limit value as 3.03. Significant changes have not been found in neither PLR nor NLR in the study of Sargin et al (18).

A number of studies have revealed the increase of MPV in patients with the GDM $(13,14,19)$ however this issue is also contradictory. Sahbaz et al (11) have conducted a retrospective study on 59 GDM patients and the MPV level was higher than the level of healthy group but Erdogan et al (10) have not found a significant change in their study in patients with GDM. We have not found a significant change of MPV in our study, neither. On the other hand, the close relationship between platelet distribution width and mean platelet volume which is shown in almost all studies, is seen in our study as well.

In our study we have found out that the platelet distribution width was a better marker than RDW, MPV, NLR and PLR in predicting GDM and we determined the PDW threshold limit as 14.75. In the study of Erdogan et al (10) the PDW was found significantly higher as well and the values were consistent with the values that we found. This study is similar to ours in terms of MPV and PDW. In our study the MPV was meaningless as

East J Med Volume:21, Number:4, October-December/2016 
well and PDW was determined significantly higher.

The exact match of age, gestational age and BMI between the patient and the control groups is considered as the strong aspect of our study. On the other hand the relatively small number of people included to the study is considered as the weak point of our study.

In conclusion, our study states that in prediction of GDM, the parameters such as PDW, PLR and NLR are more significant than the others. We determined the PDW is the best of them. These findings draw attention to the inflammation in the pathogenesis. In this regard, there is a need for larger studies that will use a larger number of patients.

\section{References}

1. Hartling L, Dryden DM, Guthrie A, et al. Screening and diagnosing gestational diabetes mellitus. Evid Rep Technol Assess (Full Rep) 2012; 210: 1-327.

2. Pettitt DJ, Baird HR, Aleck KA, Bennett PH, Knowler WC. Excessive obesity in offspring of Pima Indian women with diabetes during pregnancy. N Engl J Med 1983; 308: 242-245.

3. Retnakaran R. Glucose tolerance status in pregnancy: A window to the future risk of diabetes and cardiovascular disease in young women. Curr Diabetes Rev 2009; 5: 239-244.

4. Aktulay A, Engin-Ustun Y, Ozkan MS, et al. Gestational diabetes mellitus seems to be associated with inflammation. Acta Clin Croat 2015; 54: 475-478.

5. Coban E, Ozdogan M, Yazicioglu G, Akcit F. The mean platelet volume in patients with obesity. Int J Clin Pract 2005; 59: 981-982.

6. Papanas N, Symeonidis G, Maltezos E, et al. Mean platelet volume in patients with type 2 diabetes mellitus. Platelets 2004; 15: 475-478.

7. Coban E, Bostan F, Ozdogan M. The mean platelet volume in subjects with impaired fasting glucose. Platelets 2006; 17: 67-69.

8. Patel KV, Semba RD, Ferrucci L, et al. Red cell distribution width and mortality in older adults: a meta-analysis. J Gerontol A Biol Sci Med Sci 2010; 65: 258-265.

9. Nagababu E, Mohanty JG, Bhamidipaty S, Ostera GR, Rifkind JM. Role of the membrane in the formation of heme degradation products in red blood cells. Life Sci 2010; 86: 133-138.

10. Erdogan S, Ozdemir O, Dogan HO, et al. Liver enzymes, mean platelet volume, and red cell distribution width in gestational diabetes. Turkish Journal of Medical Science 2014; 44: 121-125.

11. Sahbaz A, Cicekler H, Aynioglu O, Isik H, Ozmen U. Comparison of the predictive value of plateletcrit with various other blood parameters in gestational diabetes development. J Obstet Gynaecol 2016; 36: 589-593.

12. Tsiara S, Elisaf M, Jagroop IA, Mikhailidis DP. Platelets as predictors of vascular risk: Is there a practical index of platelet activity? Clinical and Applied Thrombosis/ Hemostasis 2003; 9: 177-190.

13. Bozkurt N, Yilmaz E, Biri A, Taner Z, Himmetoğlu O. The mean platelet volume in gestational diabetes. J Thromb Thrombolysis 2006; 22: 51-54.

14. Erikçi AA, Muhçu M, Dündar O, Oztürk A. Could mean platelet volume be a predictive marker for gestational diabetes mellitus? Hematology 2008; 13 : 46-48.

15. Yang $\mathrm{H}$, Zhu C, Ma Q, Long Y, Cheng Z. Variations of blood cells in prediction of gestational diabetes mellitus. J Perinat Med 2015; 43: 89-93.

16. Demirtas L, Degirmenci $\mathrm{H}$, Akbas EM, et al. Association of hematological indicies with diabetes, impaired glucose regulation and microvascular complications of diabetes. Int J Clin Exp Med 2015; 8: 11420-11427.

17. Yilmaz H, Celik HT, Namuslu M, et al. Benefits of the neutrophil-to-lymphocyte ratio for the prediction of gestational diabetes mellitus in pregnant women. Experimental and Clinical Endocrinology \& Diabetes 2014; 122: 39-43.

18. Sargin MA, Yassa M, Taymur BD, et al. Neutrophilto-lymphocyte and platelet-to-lymphocyte ratios: are they useful for predicting gestational diabetesmellitus during pregnancy? Ther Clin Risk Manag 2016; 12: 657-665.

19. Iyidir OT, Degertekin CK, Yilmaz BA, et al. Elevated mean platelet volume is associated with gestational diabetes mellitus. Gynecol Endocrinol 2014; 30: 640-643. 